\title{
Reactivity of Aliphatic and Phenolic Hydroxyl Groups in Kraft Lignin towards $4,4^{\prime} \mathrm{MDI}$
}

\author{
Leonardo Dalseno Antonino $\left.{ }^{1}{ }^{(}\right)$, Júlia Rocha Gouveia ${ }^{1}{ }^{\mathbb{D}}$, Rogério Ramos de Sousa Júnior ${ }^{1}{ }^{(D}$, Guilherme Elias \\ Saltarelli Garcia ${ }^{1}$, Luara Carneiro Gobbo ${ }^{1}$, Lara Basílio Tavares ${ }^{1}$ and Demetrio Jackson dos Santos ${ }^{1,2, *}$
}

1 Nanoscience and Advanced Materials Graduate Program (PPG-Nano), Federal University of ABC (UFABC), Santo André 09210-580, Brazil; leonardo.dalseno@aluno.ufabc.edu.br (L.D.A.); juliargouveia@gmail.com (J.R.G.); rogerio.sousa@ufabc.edu.br (R.R.d.S.J.); guilherme.elias@aluno.ufabc.edu.br (G.E.S.G.); gobbo.luara@aluno.ufabc.edu.br (L.C.G.); lara.btavares@hotmail.com (L.B.T.)

2 Materials Engineering Graduate Program (PPG-Nano), Federal University of ABC (UFABC), Santo André 09210-580, Brazil

* Correspondence: demetrio.santos@ufabc.edu.br

\section{check for} updates

Citation: Antonino, L.D.; Gouveia, J.R.; de Sousa Júnior, R.R.; Garcia, G.E.S.; Gobbo, L.C.; Tavares, L.B.; dos Santos, D.J. Reactivity of Aliphatic and Phenolic Hydroxyl Groups in Kraft Lignin towards 4,4' MDI. Molecules 2021, 26, 2131. https://doi.org/10.3390/ molecules 26082131

Academic Editors: Margit Schulze and Birgit Kamm

Received: 8 March 2021

Accepted: 1 April 2021

Published: 7 April 2021

Publisher's Note: MDPI stays neutral with regard to jurisdictional claims in published maps and institutional affiliations.

Copyright: (c) 2021 by the authors. Licensee MDPI, Basel, Switzerland. This article is an open access article distributed under the terms and conditions of the Creative Commons Attribution (CC BY) license (https:/ / creativecommons.org/licenses/by/ $4.0 /)$.

\begin{abstract}
Several efforts have been dedicated to the development of lignin-based polyurethanes (PU) in recent years. The low and heterogeneous reactivity of lignin hydroxyl groups towards diisocyanates, arising from their highly complex chemical structure, limits the application of this biopolymer in PU synthesis. Besides the well-known differences in the reactivity of aliphatic and aromatic hydroxyl groups, experimental work in which the reactivity of both types of hydroxyl, especially the aromatic ones present in syringyl (S-unit), guaiacyl (G-unit), and p-hydroxyphenyl (H-unit) building units are considered and compared, is still lacking in the literature. In this work, the hydroxyl reactivity of two kraft lignin grades towards 4,4'-diphenylmethane diisocyanate (MDI) was investigated. ${ }^{31} \mathrm{P}$ NMR allowed the monitoring of the reactivity of each hydroxyl group in the lignin structure. FTIR spectra revealed the evolution of peaks related to hydroxyl consumption and urethane formation. These results might support new PU developments, including the use of unmodified lignin and the synthesis of MDI-functionalized biopolymers or prepolymers.
\end{abstract}

Keywords: lignin-based polyurethanes; chemical reactivity; hydroxyl group

\section{Introduction}

Polyurethanes (PUs) are polymers conventionally synthesized through reactions between polyols and diisocyanates. Traditionally, the precursors are derived from petroleum [1]. During the last decades, the development of biobased PUs has attracted significant efforts due to economic and social appeal for sustainable development. Among the renewable precursors, lignin has been standing out, once the resulting material combines the properties of this biopolymer with the polyurethane versatility. Recent technologies for lignin isolation accelerated the scientific and technological interest in lignin. After all, technical grade lignin is readily available on an industrial scale, with low variation in structure and properties. To date, lignin-based polyurethanes were proposed for elastomers [2-4], thermoplastics [5-8], adhesives [7,9-12], coatings [13,14] and foam formulations [15-18], among other applications.

Lignin is an abundant natural polymer present in plant cells, together with cellulose and hemicellulose. Its amorphous structure is mainly composed by guaiacyl (Gunit), syringyl (S-unit) and $p$-hydroxyphenyl (H-unit) aromatic units, which are linked by carbon-carbon $(\beta-5,5-5, \beta-1$ and $\beta-\beta)$ and carbon-oxygen linkages $(\beta-\mathrm{O}-4, \alpha-\mathrm{O}-4$ and 4-O-5) [19]. In addition, lignin also presents several functional groups: aliphatic and phenolic hydroxyls, carboxyl and methoxyl groups. There are innumerous possible combinations between basic units arising from different synthetic pathways, which make the 
macromolecule structure complex and heterogeneous [20]. Lignin structure is illustrated in Figure 1. The principal chemical linkages and functional groups are highlighted.

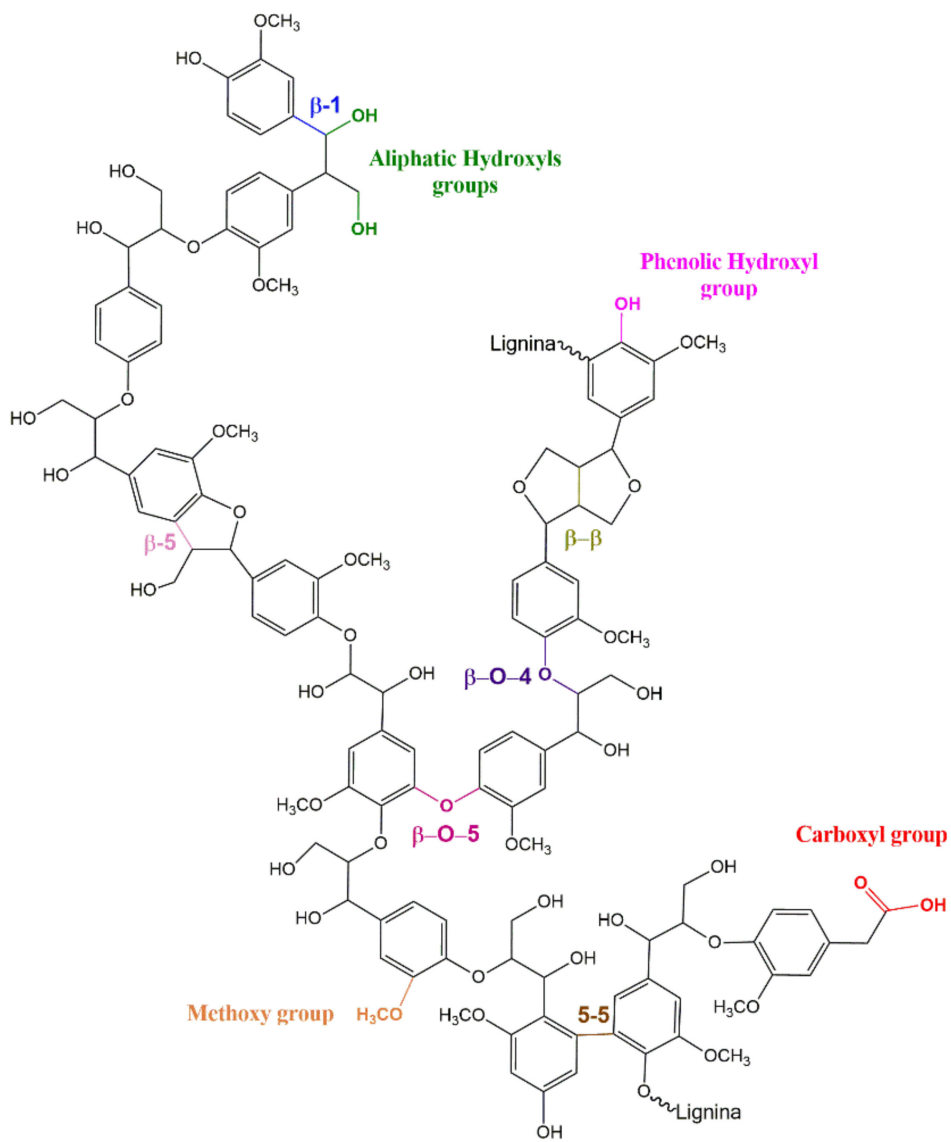

Figure 1. Lignin chemical structure representation. Adapted from Crestini et al. [21].

Looking specifically at hydroxyl groups, which are the most reactive functional groups of lignin, they promptly react with diisocyanates to form polyurethanes. The reaction mechanism is based on the nucleophilic attack of oxygen from hydroxyl groups on the electrophilic carbon of isocyanate groups [22]. A schematic representation of lignin and $4,4^{\prime}$ MDI is depicted in Figure 2. Hydroxyl groups are abundant in the lignin structure and they have different types randomly allocated, with several levels of reactivity towards diisocyanate. The main hydroxyl groups in lignin are aliphatic $(\mathrm{R}-\mathrm{OH})$ and phenolic $(\mathrm{Ph}-$ $\mathrm{OH})$. There are also carboxyl ones (R-COOH), but in smaller quantities. Concerning the phenolic hydroxyl groups, they can be divided into four types, according to the unit they are in: syringyl, noncondensed and condensed guaiacyl, and $p$-hydroxyphenyl (Figure 3). Since each $\mathrm{Ph}-\mathrm{OH}$ type is located in different chemical environments, differences in their reactivity are expected. For this reason, lignin hydroxyl reactivity plays a central role in polyurethane synthesis and might result in phase separation and unsuitable mechanical and thermal properties, if it is neglected during PU formulation and synthesis $[5,20]$. 


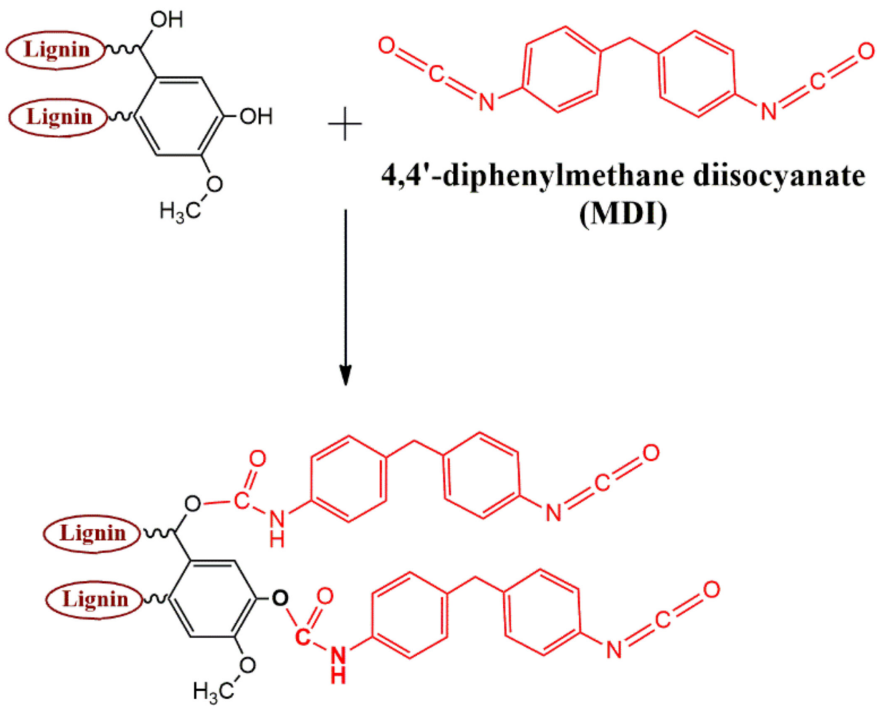

Lignin-based PU prepolymer

Figure 2. Urethanization reaction of lignin with $4,4^{\prime}$-diphenylmethane diisocyanate (MDI).<smiles></smiles>

Syringyl unit<smiles>COc1cc(C2CCCC2)ccc1O</smiles>

Non-condensed Guaiacyl unit

Condensed Guaiacyl unit (5-substituted)

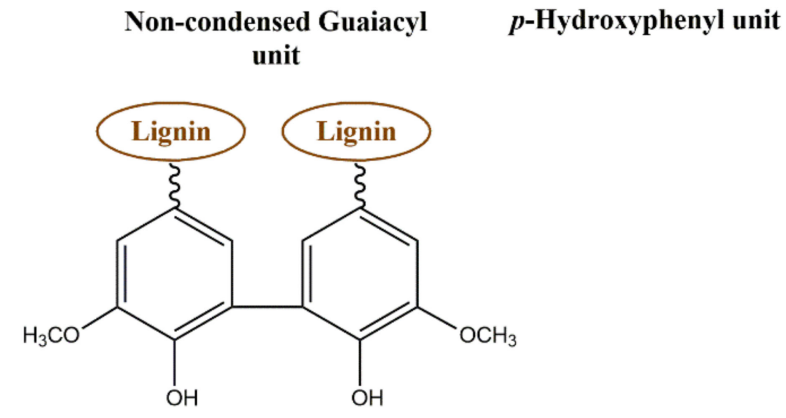<smiles>CC1CCCC1</smiles>

p-Hydroxyphenyl unit

Figure 3. Main types of lignin phenolic $\mathrm{OH}$ groups.

Considerable scientific efforts have been devoted to control lignin hydroxyl reactivity, which have triggered many modification methods, such as hydroxypropylation $[9,15,23]$, esterification [24] and acetylation [6,7], among other reactions [8]. Indeed, some modification methods successfully converted aromatic hydroxyls into aliphatic ones, minimizing the difference in hydroxyl reactivity levels. More recently, some works reported the partial lignin functionalization with diisocyanate, in which isocyanate-functionalized lignin was developed, with high performance in foams and blend formulations [25-27].

Zieglowski et al. [27] prepared different lignin-based isocyanate prepolymers by the modification of Kraft lignin with various diisocyanate compounds. The prepolymers were employed for PU foam synthesis. Additionally, the influence of the diisocyanate molecular structures on the thermomechanical properties and crosslinking reactivity (number of reactive NCO groups during self-crosslinking) was evaluated. However, the reactivity of lignin 
hydroxyl groups in modification reactions with diisocyanates has not been completely elucidated yet, mainly regarding the selectivity of the isocyanate group for the aliphatic and phenolic hydroxyl groups. Furthermore, the reactivity against isocyanate of different types of phenolic hydroxyls (Figure 3 ) is scarcely explored in the literature.

Aiming to contribute to the development of lignin-based PUs, this work investigates the reactivity of different lignin-OH groups toward $4.4^{\prime}$ diphenylmethane diisocyanate (MDI). Two technical grade lignins were used, which were obtained from the same industrial process but with differences in $\mathrm{pH}$, molar mass and hydroxyl indexes. The reactivity of each type of $-\mathrm{OH}$ was first investigated by nuclear magnetic resonance spectroscopy $\left({ }^{31} \mathrm{P}\right.$ NMR). Fourier transform infrared spectroscopy (FTIR) was performed to support the NMR results. The experimental elucidation conducted could assist in the lignin-isocyanate prepolymers synthesis and, consequently, in the lignin-based PU production, contributing to lignin revalorization.

\section{Experimental Procedures}

\subsection{Materials}

Two types of technical grade Kraft lignin (eucalyptus hardwood) were kindly supplied by Suzano S.A. (Limeira SP, Brazil), with differences in terms of $\mathrm{pH}$, molar mass and $-\mathrm{OH}$ content. the biopolymers were designated as Acid Kraft Lignin (Ac_KL, $\mathrm{pH}=$ $3.5,5.61 \mathrm{mmol} / \mathrm{g}$ of $-\mathrm{OH}$ groups, Mw of $2080 \mathrm{~g} / \mathrm{mol}$ ), and Alkali Kraft Lignin (Alk_KL, $\mathrm{pH}=8.1,5.14 \mathrm{mmol} / \mathrm{g}$ of $\mathrm{OH}$ groups and $\mathrm{Mw}$ of $2830 \mathrm{~g} / \mathrm{mol})$. The $\mathrm{pH}$ and $\mathrm{Mw}$ values were informed by the supplier, whereas the -OH content was obtained from ${ }^{31} \mathrm{P}$ NMR quantitative analysis, which is described subsequently. The lignins are isolated from different steps during the extraction process by acidification. According to the supplier, both lignin types exhibit structural repeatability and reproducibility. Tetrahydrofuran (THF), which was used as a solvent, was purchased from Labsynth (Diadema, Brazil). 4,4'-diphenylmethane diisocyanate (MDI) with $33.6 \% \mathrm{NCO}$ groups (value provided by the supplier), $N$-Hydroxy-5-norbornene-2,3-dicarboximide, $N, N$-Dimethylformamide, Pyridine, Chloroform-d, Chromium(III) acetylacetonate and 2-Chloro-4,4,5,5-tetramethyl-1,3,2dioxaphospholane were used for NMR analysis were purchased from Sigma Aldrich and used as received.

\subsection{Sample Preparation}

The synthesis of isocyanate-functionalized Kraft lignin was based on the procedure previously reported by Chauhan et al. [25]. The lignin samples were previously dried for $24 \mathrm{~h}$ in an oven with air circulation at $80^{\circ} \mathrm{C}$ to eliminate moisture. In short, $10 \mathrm{~g}$ of each type of KL was separately added to $250 \mathrm{~mL}$ three-necked round bottom flasks containing $40 \mathrm{~mL}$ of THF (inert solvent [25]). Excess of MDI (8:1 ratio between NCO:OH groups) was added to the systems stepwise. The reactions occurred in a closed system under reflux were conducted in air, under stirring at $66^{\circ} \mathrm{C}$ (THF's boiling point [28]), and in an oil bath (glycerol). Temperature variations arising from the exothermic nature of the reactions were neglected. Lignin samples were collected at different time intervals: 15, 30, 60, and $90 \mathrm{~min}$. The modified KL samples were named according to the type of lignin (Ac_KL or Alk_KL) followed by the corresponding reaction time.

\section{3. ${ }^{31} \mathrm{P}$ Nuclear Magnetic Resonance $\left({ }^{31} \mathrm{P}\right.$ NMR)}

Quantitative ${ }^{31} \mathrm{P}$ NMR spectroscopy (São Carlos, SP, Brazil) was performed to determine the consumption of $-\mathrm{OH}$ groups on both types of lignin. The preparation of samples was based on Granata and Argyropoulos work [29], with minor modifications to the procedure: $30 \mathrm{mg}$ of $\mathrm{KL}$ was added to $100 \mu \mathrm{L}$ of endo-N-hydroxy-5-norbornene2,3-dicarboximide (internal standard) [30]. A solvent mixture of pyridine and deuterated chloroform $(1.6: 1 \mathrm{v} / \mathrm{v})$, and relaxation agent chromium acetylacetonate $(16.35 \mathrm{mM})$ were added to the system, which was kept under stirring until complete solubilization of lignin. Finally, 2-chloro-4,4,5,5-tetramethyl-1,3,2-dioxaphospholane (phosphorylating agent) were 
added to the lignin solution. After solution homogenization, NMR spectra were obtained immediately on a $400 \mathrm{MHz}$ Avance III spectrometer (Bruker BioSpin, Billerica, Massachusetts, United State of America) operating with zgpg30 pulse program (Bruker BioSpin, Billerica, Massachusetts, United State of America) and the following acquisition parameters were used: $25^{\circ} \mathrm{C}, 512$ scans and $25 \mathrm{~s}$ delay between pulses. Automatic phase and baseline corrections were performed.

\subsection{Fourier Transform Infrared Spectroscopy (FTIR)}

FTIR-ATR measurements were performed to support the NMR results, based on the consumption of $\mathrm{OH}$ groups and appearance of other groups, such as $-\mathrm{NH}$ and $=\mathrm{C}-\mathrm{O}$, which could be assigned to urethane and urea formation. The analyses were carried out using Spectrum Two (Perkin Elmer, Waltham, Massachusetts, United States of America) equipment in attenuated total reflection (ATR) mode. A total of 32 scans were performed from 4000 to $500 \mathrm{~cm}^{-1}$ with a resolution of $4 \mathrm{~cm}^{-1}$.

\section{Results and Discussion}

\section{1. ${ }^{31} P N M R$}

The initial -OH content of both lignin samples are indicated in Table 1.

Table 1. Hydroxyl content of lignin samples (obtained from ${ }^{31} \mathrm{P}$ NMR analysis).

\begin{tabular}{cccccccc}
\hline \multirow{2}{*}{$\begin{array}{c}\text { Lignin } \\
\text { Sample }\end{array}$} & $\begin{array}{c}\text { Aliphatic } \\
\text { OH } \\
(\mathbf{m m o l} / \mathbf{g})\end{array}$ & Syringyl & $\begin{array}{c}\text { Condensed } \\
\text { Guaiacyl }\end{array}$ & $\begin{array}{c}\text { Uncondensed } \\
\text { Guaiacyl }\end{array}$ & $\begin{array}{c}\boldsymbol{p} \text {-Hydroxy } \\
\text { Phenyl }\end{array}$ & $\begin{array}{c}\text { Total } \\
\text { Phenolics }\end{array}$ & $\begin{array}{c}\text { Total OH } \\
(\mathbf{m m o l} / \mathrm{g})\end{array}$ \\
\cline { 3 - 8 } & & 2.28 & 1.11 & 0.99 & 0.13 & 4.50 & 5.61 \\
AC_KL & 1.11 & 2.05 & 1.07 & 0.9 & 0.13 & 4.14 & 5.14 \\
Alk_KL & 1.00 & & & &
\end{tabular}

The lignin hydroxyl groups' consumption as a function of reaction time was determined by ${ }^{31} \mathrm{P}$ NMR quantitative analysis. The data were compiled and are presented in Figure 1. The results indicated heterogeneous reactivity of lignin-OH groups, the major limitation for its use in polymers synthesis, such as polyurethanes [27,31]. A significant difference between aliphatic (Figure 4a) and phenolic hydroxyl groups (Figure $4 \mathrm{~b}$ ) reactivity was observed for both lignin samples. The aliphatic hydroxyl group was totally consumed in $30 \mathrm{~min}$ for both lignins, while unreacted phenolic-OH group was verified even after $90 \mathrm{~min}$ for both samples. The lower reactivity of phenolic hydroxyl groups towards isocyanates is related to their pronounced acid character compared to its aliphatic counterparts, as well as to steric hindrance effects [22,32]. Usually, the reactivity of aliphatic $-\mathrm{OH}$ groups can be up to 1000 times greater in noncatalyzed reactions with isocyanates at room temperature, in comparison with phenolic $-\mathrm{OH}$ groups [33]. In addition, the phenolic $-\mathrm{OH}$ consumption rate drastically decreased after $30 \mathrm{~min}$. At this time, all the aliphatic $-\mathrm{OH}$ was consumed, while the phenolic-OH consumption was $92 \%$ and $72 \%$ for Ac_KL and Alk_KL, respectively. The lower reaction rate after $30 \mathrm{~min}$ might be justified by the steric hindrance, which increased after lignin and MDI reaction. 


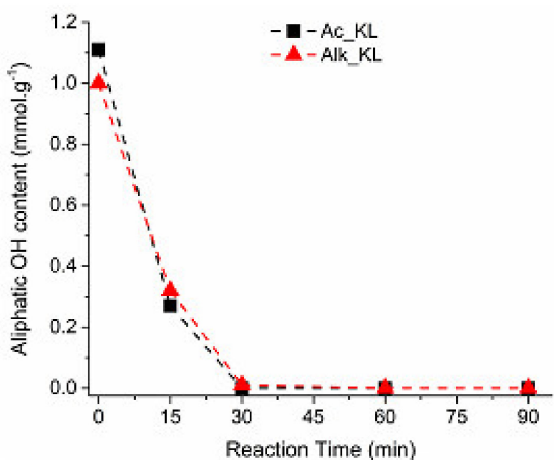

(a)

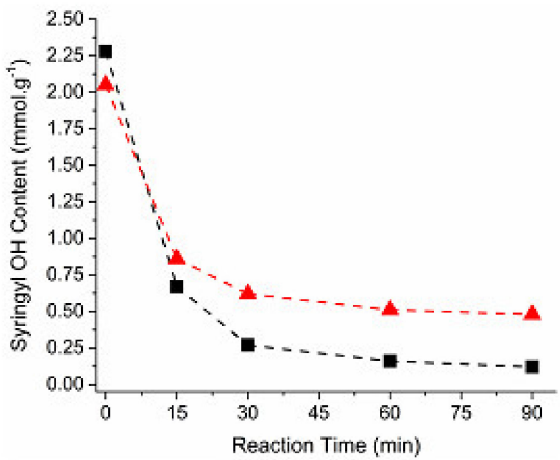

(c)

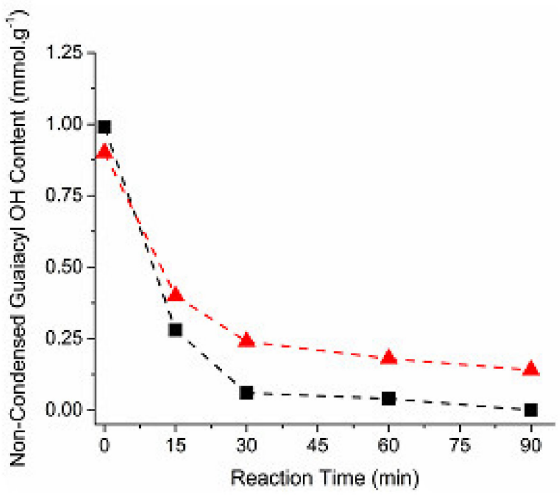

(e)

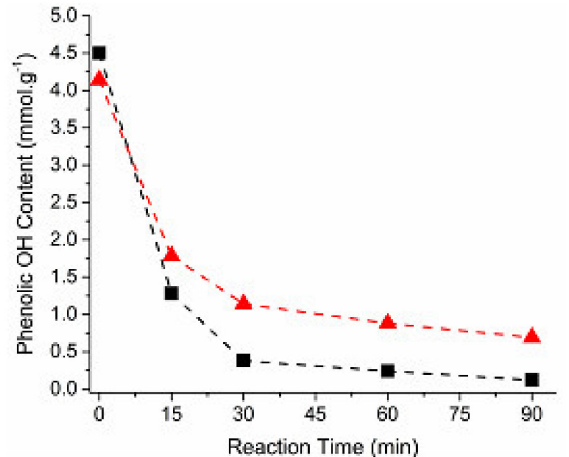

(b)

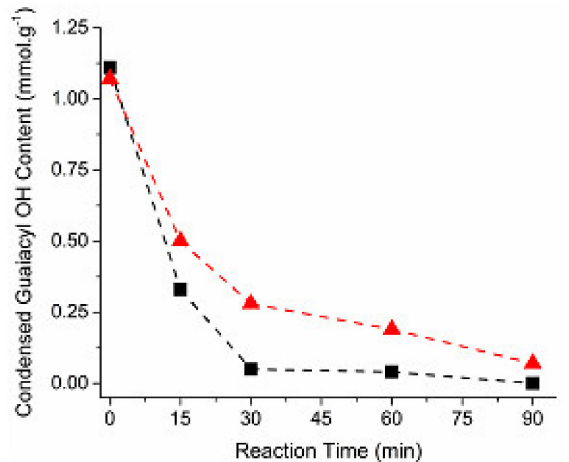

(d)

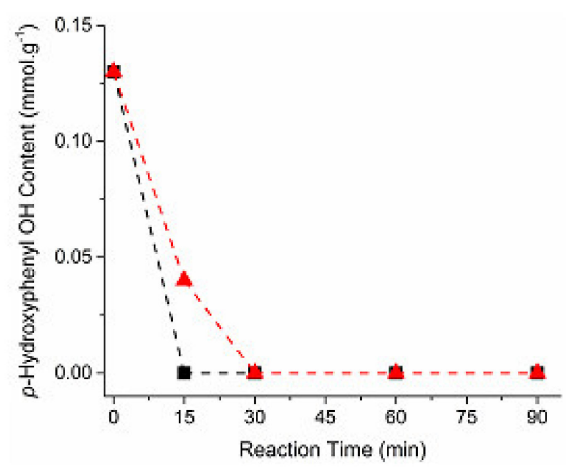

(f)

Figure 4. Evolution of hydroxyl group consumption as a function of reaction time during the reaction of Ac_KL and Alk_KL with MDI: (a) aliphatic hydroxyl group; (b) phenolic hydroxyl group (total); (c) syringyl phenolic hydroxyl group; (d) condensed guaiacyl phenolic hydroxyl group; (e) noncondensed guaiacyl phenolic hydroxyl group; (f) $p$-hydroxyphenyl phenolic hydroxyl group.

Differences in reactivity were also observed considering lignin units phenolic hydroxyls, as shown in Figure $4 \mathrm{c}-\mathrm{f}$. Firstly, the $p$-hydroxyphenyl -OH group exhibited the highest reactivity ( $100 \%$ consumed after $15 \mathrm{~min})$, whereas the syringyl unit showed the lowest reactivity ( $94.7 \%$ reacted after $90 \mathrm{~min})$. The condensed and noncondensed guaiacyl $-\mathrm{OH}$ group showed similar reactivity (both of them were totally consumed after $90 \mathrm{~min}$ ). For the alkaline lignin type, a similar trend was noted, except for the noncondensed and condensed guaiacyl $-\mathrm{OH}$ group, in which the latter presented a higher reactivity $(84.4 \%$ and $93.5 \%$ reacted after $90 \mathrm{~min}$, respectively). This trend is explained by steric hindrance effects acting on lignin phenolic -OH groups [34]. Syringyl, guaiacyl and $p$-hydroxyphenyl phenolic 
-OH groups have two, one and zero adjacent methoxy groups, respectively (Figure 3). A more pronounced steric hindrance effect is then expected as follows: syringyl > guaiacyl > $p$-hydroxyphenyl-OH groups. Therefore, the reactivity of those groups follows the inverse order, i.e., $p$-hydroxyphenyl $>$ guaiacyl $>$ syringyl $-\mathrm{OH}$ groups. The reactivity of condensed guaiacyl $-\mathrm{OH}$ group depends to which aromatic ring position other lignin units are linked (only 5 substituted is illustrated in Figure 3) [35]. There are few studies that investigate the reactivity of different types of lignin phenolic $-\mathrm{OH}$ groups towards isocyanates using macromolecular models. Most works reported in literature employ models with low molecular weight compounds, as $p$-coumarol, coniferol and sinapol (lignin precursors), and other compounds similar to lignin building blocks, such as guaycol and syringol [22,34,36-38].

Comparing the reactivity between Ac_KL and Alk_KL, the first seemed to be more reactive. After $90 \mathrm{~min}$, almost $98 \%$ of total $-\mathrm{OH}$ groups from Ac_KL were consumed, whereas for Alk_KL this value was down to $87 \%$. Lower molar mass and a higher amount of -OH groups are probably the principal factors that explain the greater reactivity towards MDI of acid lignin type $[39,40]$. The mobility of chains of low molar mass polymers is greater than high molar mass ones. Then, the -OH groups are more accessible in the Ac_KL than in the Alk_KL, since the MDI diffusion is more favorable in the former. Structural differences also affect the reactivity of lignin-OH groups. For example, syringyl-to-guaiacyl ratio (S/G ratio) and the amount of key linkages, such as $\beta-\mathrm{O}-4$ linkage, are structural factors that affect lignin reactivity [41]. Therefore, structural changes associated with distinct stages in which acid and alkaline lignins are isolated during the Kraft process can also justify the difference of reactivity between both lignin types.

Herein, the reactivity of $-\mathrm{OH}$ groups were evaluated in the context of direct urethanization of lignin with an excess of MDI (NCO:OH = 8). In PU syntheses, in which lower $\mathrm{NCO}: \mathrm{OH}$ molar ratio and chain extenders (usually polyols with low molecular weight) are employed, the reactivity of these groups is expected to be reduced. Besides lower NCO:OH molar ratio, the expected reduction in lignin-OH group reactivity during PU synthesis is also due to the increase of steric hindrance effect and system viscosity associated with chemical crosslinking [1,32]. The first factor makes -OH groups of lignin less accessible, whereas the second one restricts the diisocyanate and lignin polymer chain diffusion in the reaction medium. For this reason, the reactivity of $-\mathrm{OH}$ groups are different when it is evaluated in the context of PU synthesis and direct urethanization, and, thus, should not be compared.

\subsection{FTIR-ATR}

The FTIR-ATR spectra of the pristine lignin (Ac_KL and Alk_KL) and their MDImodified counterpart are shown in Figures 5 and 6, while the main bands and their corresponding assignment are summarized in Table 2.

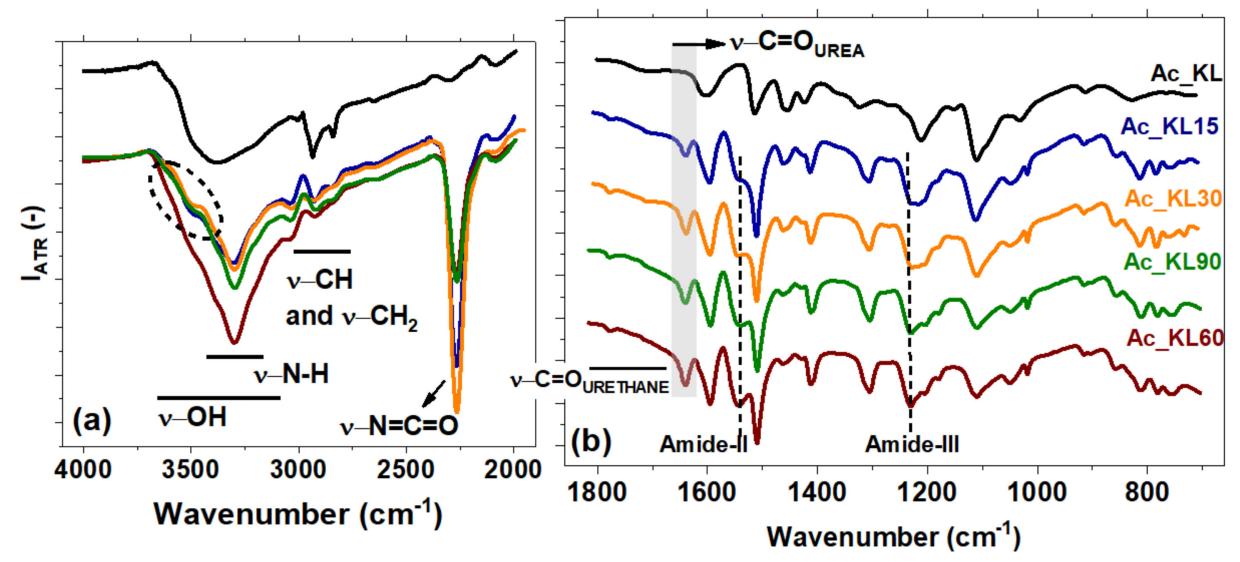

Figure 5. FTIR-ATR spectra of pristine and the derivatized Ac_KL. For clarification, the spectra are shown in two regions (a) $4000-1900 \mathrm{~cm}^{-1}$ and (b) $1800-750 \mathrm{~cm}^{-1}$. 

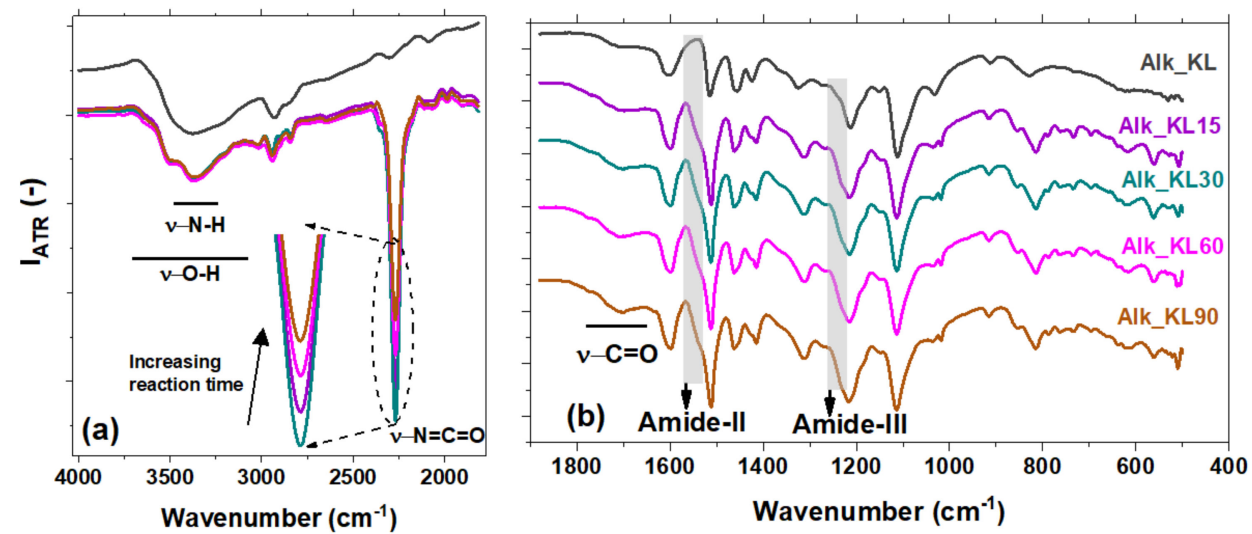

Figure 6. FTIR-ATR spectra of pristine and the derivatized Alk_KL. For clarification, the spectra are shown in two regions (a) $4000-1900 \mathrm{~cm}^{-1}$ and (b) $1800-450 \mathrm{~cm}^{-1}$.

Table 2. Main IR bands assignment of the initial KL and KL-MDI functionalized samples.

\begin{tabular}{|c|c|}
\hline Band Positions $\left(\mathrm{cm}^{-1}\right)$ & Assignment \\
\hline 3400 & $-\mathrm{OH}$ stretching of aromatic and aliphatic \\
\hline 3300 & -NH amine stretching \\
\hline 2930 & $\begin{array}{l}\text { - } \mathrm{CH} \text { asymmetric stretching vibration of } \\
\text { methyl/methylene groups }\end{array}$ \\
\hline 2840 & $\begin{array}{l}\text {-CH symmetric stretching of } \\
\text { methyl/methylene groups }\end{array}$ \\
\hline 2270 & $-\mathrm{N}=\mathrm{C}=\mathrm{O}$ isocyanate asymmetric stretching \\
\hline $1765-1650$ & $-\mathrm{C}=\mathrm{O}$ urethane carbonyl stretching vibration \\
\hline 1702 & $-\mathrm{C}=\mathrm{O}$ lignin carbonyl stretching vibration \\
\hline 1640 & $-\mathrm{C}=\mathrm{O}$ urea carbonyl stretching vibration \\
\hline 1540 & Amide II \\
\hline 1235 & Amide III \\
\hline
\end{tabular}

Because the type of parental lignin affected considerably the reaction with MDI as addressed in the previous section, they will be discussed separately. In the case of the Ac_KL series, several peak changes could be assigned to the urethane formation. In the Ac_KL spectrum, a broad peak attributed to the hydroxyl absorption was found in the region comprised between $3600 \mathrm{~cm}^{-1}$ and $3000 \mathrm{~cm}^{-1}$. Already at $15 \mathrm{~min}$, this region was marked by the appearance of a sharp peak centered at $3300 \mathrm{~cm}^{-1}$, assigned to the amine stretching vibration, which is characteristic of the urethane group [42], whereas a shoulder related to the $-\mathrm{OH}$ vibration could still be seen (indicated by the dashed circle in Figure $5 a)$. As the reaction proceeds, the $-\mathrm{OH}$ absorption band became less pronounced and disappeared (Ac_KL90 spectra, wine line). The peaks at $2930 \mathrm{~cm}^{-1}$ and $2840 \mathrm{~cm}^{-1}$ are typically found in the lignin spectra and were assigned to the asymmetric and symmetric vibration of $-\mathrm{CH} 2$ and $-\mathrm{CH} 3$ groups [43]. The prominent band assigned at $2270 \mathrm{~cm}^{-1}$ was attributed to the isocyanate stretching vibration and could be used to estimate kinetic data provided that the spectra are normalized. In this work, we could not find a reference band that could be employed for spectra normalization; therefore, no semi-quantitative analysis could be performed with the FTIR-ATR technique.

The region between $1800 \mathrm{~cm}^{-1}$ and $1600 \mathrm{~cm}^{-1}$ corresponds to the carbonyl stretching vibration and is of uttermost importance for the investigation of polyurethanes and polyureas. The Ac_KL spectrum showed a small broad peak centered at $1702 \mathrm{~cm}^{-1}$, assigned to $-\mathrm{C}=\mathrm{O}$ band that is present in lignin structure. After reaction with $\mathrm{MDI}$, the 
carbonyl bands broadened and shifted to higher wavenumbers. As depicted in Figure 5 (black horizontal line), the $-\mathrm{C}=\mathrm{O}$ peak after MDI-derivatization lay within the urethane carbonyl band. The features in this region suggested the occurrence of a reaction between MDI and lignin- $\mathrm{OH}$ that led to the formation of urethane groups [7,12]. This argument is strengthened by the appearance of the so-called amide II and amide III band centered at $1540 \mathrm{~cm}^{-1}$ and $1235 \mathrm{~cm}^{-1}$, respectively (dashed line) [44]. These bands are related to the combination of the vibration of the $-\mathrm{C}-\mathrm{N}$ bond, found in the urethane group [45].

The spectra also revealed that not only urethane groups were formed, but also urea. This observation was supported by the presence of a prominent peak in the $-\mathrm{C}=\mathrm{O}$ region $\left(1640 \mathrm{~cm}^{-1}\right)$ that was attributed to urea. The urea formation is a consequence of isocyanate reaction with water. The side reaction of isocyanate with water is a well-known problem in PU synthesis. As depicted in Scheme 1, the isocyanate and water reaction happens in two stages. First, the unstable carbamic acid is formed, which is decomposed generating $\mathrm{CO}_{2}$ and an amine group in the second stage. The amine then is prone to react with the remaining isocyanate, yielding urea groups [46]. The presence of this group in the Ac_KL derivatized spectra was an indication of the presence of humidity in the reaction media. The presence of urea must be taken into account, since it may affect PUs relevant macroscopic properties [47].

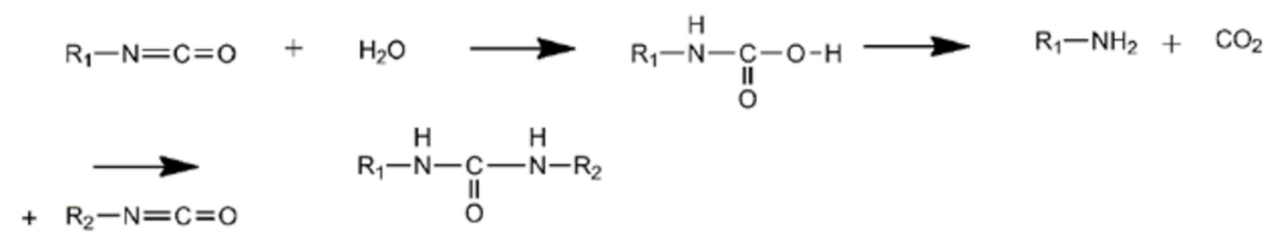

Scheme 1. Formation of urea from the reaction of isocyanate and water.

Figure 4 shows the same set of plots for the Alk_KL series. Once again, it was not possible to normalize the spectra with respect to each other; however, one may compare the proportional evolution of the peaks within the same curve. While in the Ac_KL derivatized samples the increase in the $v-\mathrm{N}-\mathrm{H}$ peak was accompanied by a decrease in the $v-\mathrm{O}-\mathrm{H}$ band, in the Alk_KL set the same proportion (i.e., $v-\mathrm{N}-\mathrm{H} / \mathrm{v}-\mathrm{O}-\mathrm{H}$ ) was kept throughout the reaction time. This trend suggested that the reaction proceeded in a fast manner in the early stages of the reaction and then reached a plateau. Curiously, the $\mathrm{N}=\mathrm{C}=\mathrm{O}$ vibration peak did not follow the same trend as the $v-\mathrm{N}-\mathrm{H} / v-\mathrm{O}-\mathrm{H}$. While the latter overlapped, the intensity of the $-\mathrm{N}=\mathrm{C}=\mathrm{O}$ peak reduced with increasing reaction time, as highlighted by the dashed circle in Figure 6a.

The carbonyl band showed a modest increase with MDI-modification. The same was observed for amide-II and amide-III bands, which appeared only as a shoulder on the peaks from Alk_KL structure (gray rectangles in Figure 6b). Accordingly, no peak assigned to urea could be seen in the spectra. Although no indication of urea formation was identified in the spectra, we do not claim that this group was not formed during the reaction between lignin and MDI. Considering that this reaction was carried out in an open reactor, urea moieties were expected in the lignin-MDI structure, and their absence in the spectra might be a consequence of overlap between lignin/urethane and urea peaks. Collectively, these results suggest an unexpectedly lower reactivity from Alk_KL-OH moieties towards MDI in comparison to Ac_KL [48], corroborating the results obtained in NMR analysis.

\section{Conclusions}

The reactivity of different-OH groups of Kraft lignin toward 4.4' MDI was investigated. According to ${ }^{31} \mathrm{P}$ NMR analysis, aliphatic $-\mathrm{OH}$ groups of both lignin types were completely consumed after $15 \mathrm{~min}$, whereas residual aromatic ones were observed after 90 min. ${ }^{31} \mathrm{P}$ NMR also revealed a hierarchy reactivity among phenolic hydroxyl groups, in which $\mathrm{H}$ units are the most reactive, followed by $\mathrm{G}$ and $\mathrm{S}$ units. In addition, an unexpectedly high $-\mathrm{OH}$ consumption was verified for both lignin types, in all cases higher than 
$87 \%$ of total $-\mathrm{OH}$ groups after $90 \mathrm{~min}$ reaction. The most reactive lignin presented acidic $\mathrm{pH}$ and lower molar mass. FTIR-ATR spectra corroborated the NMR results, confirming a higher consumption of $-\mathrm{OH}$ groups for $\mathrm{Ac} \_\mathrm{KL}$, in which the formation of urea groups was verified. The results confirmed the well-known heterogeneous reactivity of lignin $-\mathrm{OHs}$ and suggested that lignin $\mathrm{pH}$ influences its reactivity. Although the $-\mathrm{OH}$ groups reactivity was nonuniform, a good reactivity between them and isocyanates was verified. Therefore, the unmodified Kraft lignin proved to be feasible for PU prepolymer synthesis. In conclusion, the present work contributes to the development of lignin-based PUs and it might support the development and improvement of modification methods that aim to improve lignin reactivity.

Author Contributions: Conceptualization, D.J.d.S. and L.B.T.; methodology, D.J.d.S.; software, L.D.A. and J.R.G.; valida-tion, L.D.A. and J.R.G.; formal analysis, L.D.A., J.R.G. and L.B.T.; investigation, L.D.A. and J.R.G.; data curation, L.D.A., J.R.G. and L.B.T.; writing—original draft preparation, L.D.A., L.C.G., D.J.d.S., L.B.T., and J.R.G.; writing-review and editing, L.D.A., J.R.G., L.B.T., G.E.S.G., R.R.d.S.J.; visualization, L.C.G. and D.J.d.S.; supervision, D.J.d.S.; project administration, D.J.d.S.; funding acquisition, D.J.d.S., L.D.A. and G.E.S.G. All authors have read and agreed to the published version of the manuscript.

Funding: This research was funded by The São Paulo Research Foundation FAPESP (grant numbers 2017/22936-9, 2019/05460-6 and 2020/00876-7) and the Conselho Nacional de Desenvolvimento Científico e Tecnológico CNPq (grant number 142544/2020-5).

Institutional Review Board Statement: Not applicable.

Informed Consent Statement: Not applicable.

Data Availability Statement: The data that support the findings of this study are available from the corresponding author, upon reasonable request.

Acknowledgments: We are grateful for the financial support from Conselho Nacional de Desenvolvimento Científico e Tecnológico CNPq (grant number 142544/2020-5) and São Paulo Research Foundation FAPESP (grant number 2017/22936-9 and 2019/05460-6).

Conflicts of Interest: The authors declare no conflict of interest.

Sample Availability: Samples of the compounds are available from the authors.

\section{References}

1. Alinejad, M.; Henry, C.; Nikafshar, S.; Gondaliya, A.; Bagheri, S.; Chen, N.; Singh, S.K.; Hodge, D.B.; Nejad, M. Lignin-based polyurethanes: Opportunities for bio-based foams, elastomers, coatings and adhesives. Polymers 2019, 11, 1202. [CrossRef] [PubMed]

2. Ciobanu, C.; Ungureanu, M.; Ignat, L.; Ungureanu, D.; Popa, V.I. Properties of lignin-polyurethane films prepared by casting method. Ind. Crops Prod. 2004, 20, 231-241. [CrossRef]

3. Hirose, S.; Kobashigawa, K.; Izuta, Y.; Hatakeyama, H. Thermal degradation of polyurethanes containing lignin studied by TG-FTIR. Polym. Int. 1998, 47, 247-256. [CrossRef]

4. De Silva, E.A.B.; Zabkova, M.; Araújo, J.D.; Cateto, C.A.; Barreiro, M.F.; Belgacem, M.N.; Rodrigues, A.E. An integrated process to produce vanillin and lignin-based polyurethanes from Kraft lignin. Chem. Eng. Res. Des. 2009, 87, 1276-1292. [CrossRef]

5. Gouveia, J.R.; da Costa, C.L.; Tavares, L.B.; dos Santos, D.J. Synthesis of lignin-based polyurethanes: A mini-review. Mini. Rev. Org. Chem. 2018, 16, 345-352. [CrossRef]

6. Jeong, H.; Park, J.; Kim, S.; Lee, J.; Ahn, N.; Roh, H. Preparation and characterization of thermoplastic polyurethanes using partially acetylated kraft lignin. Fibers Polym. 2013, 14, 1082-1093. [CrossRef]

7. Gouveia, J.R.; de Sousa, R.R., Jr.; Ribeiro, A.O.; Saraiva, S.A.; dos Santos, D.J. Effect of soft segment molecular weight and $\mathrm{NCO}: \mathrm{OH}$ ratio on thermomechanical properties of lignin-based thermoplastic polyurethane adhesive. Eur. Polym. J. 2020, 131, 109690. [CrossRef]

8. Saito, T.; Perkins, J.H.; Jackson, D.C.; Trammel, N.E.; Hunt, M.A.; Naskar, A.K. Development of lignin-based polyurethane thermoplastics. RSC Adv. 2013, 3, 21832-21840. [CrossRef]

9. Gouveia, J.R.; Antonino, L.D.; Garcia, G.E.S.; Tavares, L.B.; Santos, A.N.B.; Dos Santos, D.J. Kraft lignin-containing polyurethane adhesives: The role of hydroxypropylation on thermomechanical properties. J. Adhes. 2020. [CrossRef]

10. Tavares, L.B.; Boas, C.V.; Schleder, G.R.; Nacas, A.M.; Rosa, D.S.; Dos Santos, D.J. Bio-based polyurethane prepared from Kraft lignin and modified castor oil. Express Polym. Lett. 2016, 10, 927-940. [CrossRef] 
11. Gadhave, R.V.; Kasbe, P.S.; Mahanwar, P.A.; Gadekar, P.T. Synthesis and characterization of lignin-polyurethane based wood adhesive. Int. J. Adhes. Adhes. 2019, 95, 102427. [CrossRef]

12. Nacas, A.M.; Ito, N.M.; Sousa, R.R.D.; Spinacé, M.A.; Dos Santos, D.J. Effects of NCO:OH ratio on the mechanical properties and chemical structure of Kraft lignin-based polyurethane adhesive. J. Adhes. 2017, 93, 18-29. [CrossRef]

13. Chahar, S.; Dastidar, M.G.; Choudhary, V.; Sharma, D.K. Synthesis and characterisation of polyurethanes derived from waste black liquor lignin. J. Adhes. Sci. Technol. 2004, 18, 169-179. [CrossRef]

14. Griffini, G.; Passoni, V.; Suriano, R.; Levi, M.; Turri, S. Polyurethane coatings based on chemically unmodified fractionated lignin. ACS Sustain. Chem. Eng. 2015, 3, 1145-1154. [CrossRef]

15. Li, Y.; Ragauskas, A.J. Kraft lignin-based rigid polyurethane foam. J. Wood Chem. Technol. 2012, 32, 210-224. [CrossRef]

16. Bernardini, J.; Cinelli, P.; Anguillesi, I.; Coltelli, M.B.; Lazzeri, A. Flexible polyurethane foams green production employing lignin or oxypropylated lignin. Eur. Polym. J. 2015, 64, 147-156. [CrossRef]

17. Cinelli, P.; Anguillesi, I.; Lazzeri, A. Green synthesis of flexible polyurethane foams from liquefied lignin. Eur. Polym. J. 2013, 49, 1174-1184. [CrossRef]

18. Nadji, H.; Bruzzèse, C.; Belgacem, M.N.; Benaboura, A.; Gandini, A. Oxypropylation of lignins and preparation of rigid polyurethane foams from the ensuing polyols. Macromol. Mater. Eng. 2005, 290, 1009-1016. [CrossRef]

19. Calvo-Flores, F.G.; Dobado, J.A. Lignin as renewable raw material. ChemSusChem 2010, 3, 1227-1235. [CrossRef] [PubMed]

20. Glasser, W.G. About making lignin great again—Some lessons from the past. Front. Chem. 2019, 7, 1-17. [CrossRef]

21. Crestini, C.; Crucianelli, M.; Orlandi, M.; Saladino, R. Oxidative strategies in lignin chemistry: A new environmental friendly approach for the functionalisation of lignin and lignocellulosic fibers. Catal. Today 2010, 156, 8-22. [CrossRef]

22. Gandini, A.; Belgacem, M.N.; Guo, Z.-X.; Montanari, S. Lignins as Macromonomers for Polyesters and Polyurethanes. In Chemical Modification, Properties, and Usage of Lignin; Springer: Boston, MA, USA, 2002; pp. 57-80.

23. Cateto, C.A.; Barreiro, M.F.; Rodrigues, A.E.; Belgacem, M.N. Optimization study of lignin oxypropylation in view of the preparation of polyurethane rigid foams. Ind. Eng. Chem. Res. 2009, 48, 2583-2589. [CrossRef]

24. Zhang, X.; Kim, Y.; Elsayed, I.; Taylor, M.; Eberhardt, T.L.; Hassan, E.B.; Shmulsky, R. Rigid polyurethane foams containing lignin oxyalkylated with ethylene carbonate and polyethylene glycol. Ind. Crops Prod. 2019, 141, 111797. [CrossRef]

25. Chauhan, M.; Gupta, M.; Singh, B.; Singh, A.K.; Gupta, V.K. Effect of functionalized lignin on the properties of lignin-isocyanate prepolymer blends and composites. Eur. Polym. J. 2014, 52, 32-43. [CrossRef]

26. Gómez-Fernández, S.; Ugarte, L.; Calvo-Correas, T.; Peña-Rodríguez, C.; Corcuera, M.A.; Eceiza, A. Properties of flexible polyurethane foams containing isocyanate functionalized kraft lignin. Ind. Crops Prod. 2017, 100, 51-64. [CrossRef]

27. Zieglowski, M.; Trosien, S.; Rohrer, J.; Mehlhase, S.; Weber, S.; Bartels, K.; Siegert, G.; Trellenkamp, T.; Albe, K.; Biesalski, M. Reactivity of isocyanate-functionalized lignins: A key factor for the preparation of lignin-based polyurethanes. Front. Chem. 2019, 7, 1-9. [CrossRef]

28. Takahashi, M.; Yang, S.; Yamamoto, K.; Ohara, K.; Phuc, N.H.H.; Watanabe, T.; Uchiyama, T.; Sakuda, A.; Hayashi, A.; Tatsumisago, M.; et al. Improvement of lithium ionic conductivity of Li3PS4 through suppression of crystallization using low-boiling-point solvent in liquid-phase synthesis. Solid State Ion. 2021, 361, 115568. [CrossRef]

29. Granata, A.; Argyropoulos, D.S. 2-Chloro-4,4,5,5-tetramethyl-1,3,2-dioxaphospholane, a reagent for the accurate determination of the uncondensed and condensed phenolic moieties in lignins. J. Agric. Food Chem. 1995, 43, 1538-1544. [CrossRef]

30. Zawadzki, M.; Ragauskas, A. N-hydroxy compounds as new internal standards for the 31P-NMR determination of lignin hydroxy functional groups. Holzforschung 2001, 55, 283-285. [CrossRef]

31. Hofmann, K.; Glasser, W.G. Engineering plastics from lignin. 21.1 synthesis and properties of epoxidized lignin- poly (propylene oxide) copolymers. J. Wood Chem. Technol. 1993, 13, 73-95. [CrossRef]

32. Cateto, C.A.; Barreiro, M.F.; Rodrigues, A.E.; Belgacem, M.N. Kinetic study of the formation of lignin-based polyurethanes in bulk. React. Funct. Polym. 2011, 71, 863-869. [CrossRef]

33. Delebecq, E.; Pascault, J.P.; Boutevin, B.; Ganachaud, F. On the versatility of urethane/urea bonds: Reversibility, blocked isocyanate, and non-isocyanate polyurethane. Chem. Rev. 2013, 113, 80-118. [CrossRef]

34. Montanari, S.; Baradie, B.; Andréolèty, J.-P.; Gandini, A. Star-Shaped and Crosslinked Polyurethanes Derived from Lignins and Oligoether Isocyanates. In The Chemistry and Processing of Wood and Plant Fibrous Material; Elsevier: Amsterdam, The Netherlands, 1996; pp. 351-358.

35. Lundquist, K.; Parkås, J. Different types of phenolic units in lignins. BioResources 2011, 6, 920-926. [CrossRef]

36. Elrhayam, Y.; Elharfi, A. 3D-QSAR studies of the chemical modification of hydroxyl groups of biomass (cellulose, hemicelluloses and lignin) using quantum chemical descriptors. Heliyon 2019, 5, e02173. [CrossRef] [PubMed]

37. Maia, R.A.; Ventorim, G.; Batagin-Neto, A. Reactivity of lignin subunits: The influence of dehydrogenation and formation of dimeric structures. J. Mol. Model. 2019, 25, 1-11. [CrossRef]

38. Martinez, C.; Rivera, J.L.; Herrera, R.; Rico, J.L.; Flores, N.; Rutiaga, J.G.; López, P. Evaluation of the chemical reactivity in lignin precursors using the Fukui function. J. Mol. Model. 2008, 14, 77-81. [CrossRef] [PubMed]

39. Ding, Z.; Qiu, X.; Fang, Z.; Yang, D. Effect of molecular weight on the reactivity and dispersibility of sulfomethylated alkali lignin modified by horseradish peroxidase. ACS Sustain. Chem. Eng. 2018, 6, 14197-14202. [CrossRef]

40. Pan, X.; Saddler, J.N. Effect of replacing polyol by organosolv and kraft lignin on the property and structure of rigid polyurethane foam. Biotechnol. Biofuels 2013, 6, 12. [CrossRef] 
41. Jardim, J.M.; Hart, P.W.; Lucia, L.; Jameel, H. Insights into the potential of hardwood kraft lignin to be a green platform material for emergence of the biorefinery. Polymers 2020, 12, 1795. [CrossRef]

42. Zimmer, B.; Nies, C.; Schmitt, C.; Paulo, C.; Possart, W. Chemistry, polymer dynamics and mechanical properties of a two-part polyurethane elastomer during and after crosslinking. Part II: Moist conditions. Polymer 2018, 149, 238-252. [CrossRef]

43. Cachet, N.; Camy, S.; Benjelloun-Mlayah, B.; Condoret, J.S.; Delmas, M. Esterification of organosolv lignin under supercritical conditions. Ind. Crops Prod. 2014, 58, 287-297. [CrossRef]

44. Zhang, C.; Ren, Z.; Yin, Z.; Qian, H.; Ma, D. Amide II and amide III bands in polyurethane model soft and hard segments. Polym. Bull. 2008, 60, 97-101. [CrossRef]

45. Yilgör, I.; Yilgör, E.; Wilkes, G.L. Critical parameters in designing segmented polyurethanes and their effect on morphology and properties: A comprehensive review. Polymer 2015, 58, A1-A36. [CrossRef]

46. Giroto, A.S.; do Valle, S.F.; Ribeiro, T.; Ribeiro, C.; Mattoso, L.H.C. Towards urea and glycerol utilization as "building blocks" for polyurethane production: A detailed study about reactivity and structure for environmentally friendly polymer synthesis. React. Funct. Polym. 2020, 153, 104629. [CrossRef]

47. Zimmer, B.; Nies, C.; Schmitt, C.; Possart, W. Chemistry, polymer dynamics and mechanical properties of a two-part polyurethane elastomer during and after crosslinking. Part I: Dry conditions. Polymer 2017, 115, 77-95. [CrossRef]

48. Maillard, D.; Osso, E.; Faye, A.; Li, H.; Ton-That, M.T.; Stoeffler, K. Influence of lignin's pH on polyurethane flexible foam formation and how to control it. J. Appl. Polym. Sci. 2020, 138, 50319. [CrossRef] 